\title{
Expansores tisulares en reconstrucción de defectos craneofaciales. Estudio multicéntrico retrospectivo
}

\section{Tissue expansion in reconstruction of craniofacial defects. Multicenter retrospective study}

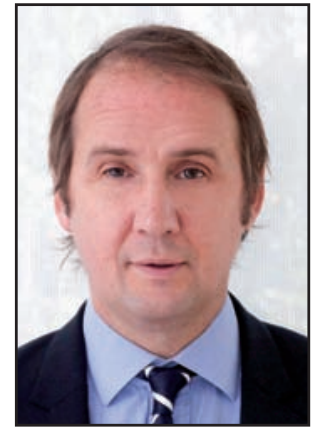

Sorolla J.P.

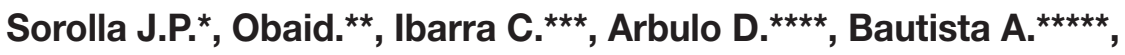

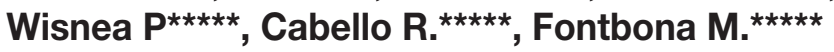

\section{Resumen}

El objetivo del presente estudio es describir y analizar el uso de expansores tisulares para reconstrucción de los defectos craneofaciales en 3 centros de alta complejidad del país (Chile).

Corresponde a un estudio descriptivo retrospectivo de pacientes tratados en el Departamento de Cirugía Plástica del Hospital Militar de Santiago, Clínica Alemana e Instituto de Neurocirugía Asenjo entre los años 2004 y 2012 por defectos en el área craneofacial. Recopilamos en un total de 37 pacientes los datos médicos, demográficos, de la operación, tiempo, volumen, número de expansores utilizados, registros fotográficos, complicaciones, volumen de sobrexpansión, y un cuestionario de satisfacción de los pacientes en relación al uso del expansor tisular.

Se obtuvo cobertura adecuada del defecto en la totalidad de los casos. En 16 pacientes $(43,2 \%)$ mediante el uso de 2 expansores tisulares; en $15(40,5 \%)$ con 1 expansor; en $4(10,8 \%)$ con 3 expansores y en 2 pacientes $(5,4 \%)$ con 4 expansores. El tiempo total de tratamiento en promedio correspondió a 70 días, con un porcentaje de complicaciones menores en un $35,1 \%$ de los casos, y mayores en un $2,7 \%$.

En relación al cuestionario aplicado, obtuvimos un 94,6\% de respuestas positivas respecto al resultado final de la cirugía; sólo un $54,1 \%$ de los pacientes recomendaría este método de expansión tisular a un tercero.

En conclusión, nuestro estudio determina que se logró un buen resultado final, con bajo porcentaje de complicaciones mayores y alto porcentaje de satisfacción en el resultado de la cirugía por parte de los pacientes. La aplicación del cuestionario, resulta útil para la obtención de información más objetiva respecto a la opinión sobre este procedimiento por parte de los pacientes.

\section{Palabras clave Craneofacial, Reconstrucción craneofacial, Expansores.}

Nivel de evidencia científica

\section{IV}

Our goal is to describe and analyze the use of tissue expanders for reconstruction of craniofacial defects in 3 highly complex centers in the country (Chile).

Corresponds to a retrospective study of patients treated at Hospital Militar de Santiago, Clinica Alemana e Instituto de Neurocirugia Asenjo between 2004 and 2012 by defects in the craniofacial area. We collected in a total of 37 patients medical data, demographic data, operation time, volume, number of expanders used, photographic records, complications, volume overexpansion, and a questionnaire regarding patients satisfaction with the use of tissue expander.

Adequate coverage of the defect was obtained in all cases. In 16 patients $(43,2 \%)$ using 2 tissue expanders; in $15(40,5 \%)$ with 1 expander; in $4(10,8 \%)$ with 3 expanders and in 2 $(5,4 \%)$ with 4 expanders. Total treatment time corresponded on average to 70 days, with a percentage of minor complications in $35,1 \%$ patients and major complications in $2,7 \%$ patients.

Regarding the applied questionnaire we obtained $94,6 \%$ of positive responses regarding the final result of the surgery; only $54,1 \%$ of the patients would recommend this method of tissue expansion to a third party.

In our study, a good final result was achieved with low rate of major complications and a high rate of satisfaction in the outcome of surgery by patients. The administration of the questionnaire is useful for obtaining more objective information regarding the review of this process by patients undergoing this surgery.

Level of evidence IV 


\section{Introducción}

La expansión tisular es un fenómeno fisiológico comúnmente observado en la práctica médica en el cual la epidermis, la dermis, el tejido celular subcutáneo y el músculo se distienden al estar sometidos a una presión constante, tal y como sucede en el caso de tumores o hematomas (1). El cirujano reconstructivo aprovecha este proceso natural para obtener un tejido donante del mismo color, textura, grosor y con sensibilidad similar, para cubrir o reconstruir un defecto tisular con una mínima morbilidad de la zona dadora.

Un expansor tisular está constituido por una bolsa o receptáculo de silicona (el expansor propiamente dicho) que se puede rellenar progresivamente con suero fisiológico para ir produciendo la expansión del tejido, y un reservorio o válvula mediante el cual se inyecta transcutáneamente la solución fisiológica que se acumulará en el expansor. Existen diferentes tamaños y una gran variedad de formas (2).

La técnica de expansión tisular se ha convertido en una herramienta útil y poderosa en Cirugía Plástica, que permite al cirujano cubrir vastas áreas corporales con tejido autólogo (3) de vecindad en cualquier segmento anatómico: cabeza, cara, cuello, tronco y extremidades (1).

La reconstrucción de los defectos craneofaciales supone un desafío quirúrgico debido a las características únicas y propias de las estructuras comprometidas; por lo tanto, presenta complicaciones específicas y exclusivas al uso de la expansión tisular en esta región, tales como elevación o ptosis de la frente con implantación anormal de cuero cabelludo (4) y alopecia (5). La técnica se emplea en defectos de este área causados por traumatismos agudos con pérdida de cobertura (6), necrosis por radiación, reparación de alopecia traumática (7), nevus melanocítico congénito (8), quemaduras, anomalías vasculares, microtia, gemelos craneópagos (6), o en cirugía estética (7), entre otros.

El objetivo de nuestro trabajo es describir y analizar el uso de expansores tisulares para la reconstrucción de defectos craneofaciales en 3 centros de alta complejidad del país (Chile), y comprobar la percepción del paciente sobre el uso de esta técnica mediante la aplicación de un cuestionario de satisfacción específicamente desarrollado para este fin.

\section{Material y método}

Realizamos un estudio retrospectivo y descriptivo en 3 centros de alta com- plejidad del país: Cirugía Plástica del Hospital Militar de Santiago, Clínica Alemana e Instituto de Neurocirugía Asenjo. Recopilamos los datos de 37 pacientes intervenidos quirúrgicamente entre los años 2004 y 2012 con diversas indicaciones para tratamiento quirúrgico en el área craneofacial.

Obtuvimos datos demográficos de sexo y edad, datos médicos y de la operación, sus complicaciones, volumen de sobrexpansión (volumen en centímetros cúbicos superior a la capacidad prevista por el expansor) $(9,10)$ y registro fotográfico. Categorizamos las complicaciones en mayores y menores; las primeras se correspondieron a todo evento adverso que significara un acto quirúrgico adicional (por ejemplo: dehiscencia de herida, exposición de expansor tisular, entre otras).

Finalmente, entregamos a los pacientes un cuestionario tipo escala de Likert (11-13), método que expresa la opinión del individuo permitiendo la agrupación de sus respuestas en una escala continua que va de positivo a negativo (de acuerdo a desacuerdo). Este cuestionario tuvo como objetivo recoger la opinión de cada paciente en relación al uso de expansores tisulares en defectos craneofaciales. Los pacientes debían responder en un ítem de respuestas de 5 niveles (por ejemplo: muy de acuerdo, de acuerdo, ni de acuerdo ni en desacuerdo, desacuerdo, muy en desacuerdo), de esta forma eliminábamos el sesgo de aquiescencia. Finalmente, los datos recogidos
Tabla I. Cuestionario de 7 preguntas en relación al uso de expansores tisulares para la reconstrucción de defectos craneofaciales

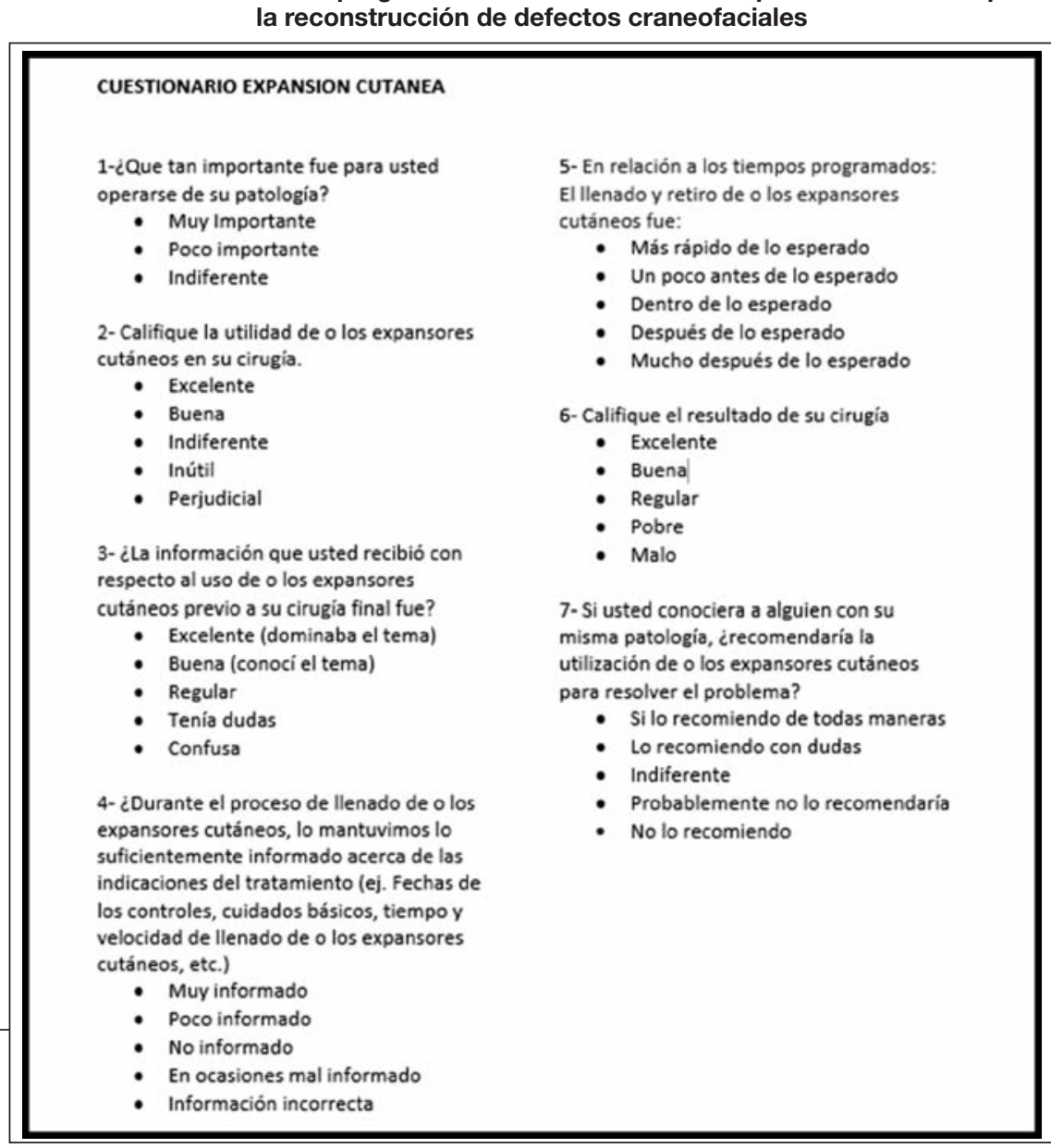


se agrupan en 3 categorías (positiva, neutra y negativa) y se realizaron mediciones para evaluar el grado de satisfacción del paciente. El cuestionario consistió en 7 preguntas que aparecen en la Tabla I.

Por otra parte, aplicamos la escala de Strasser (14) en relación al grado de satisfacción del paciente en lo que respecta al resultado de la cirugía tras el alta. Para ello utilizamos 3 observadores: madre o padre del paciente, enfermera del equipo de Cirugía Plástica y el autor principal, y se asignó un valor determinado respecto al resultado. De acuerdo a esta escala, una puntación total entre 1 y 4 correspondería a un buen resultado, entre 5 y 14 a un resultado mediocre y mayor a 15 a un resultado pobre (14).

Para el registro y análisis estadístico de los datos recopilados empleamos Data Analisis Stadistical Software (Stata 12.0), utilizando la desviación estándar como medida de dispersión de los datos respecto a la media.

Todos los pacientes dieron su consentimiento informado, o lo dieron los padres si se trataba de menores de 18 años.

\section{Procedimiento quirúrgico}

Durante el primer tiempo quirúrgico, se infiltró el área de interés con lidocaína 1\% con epinefrina 1:100.000 para disminuir el sangrado intraoperatorio. La incisión para la instalación del expansor tisular se realizó en el defecto mismo cuando se trataba de nevus melanocíticos, y en los márgenes para otro tipo de lesiones. La disección fue roma para crear un bolsillo en el que introducir el expansor empleando el plano subgaleal para defectos en el cuero cabelludo, y el plano subcutáneo para las le- siones del área facial. Se realizó otro bolsillo de menor tamaño para colocar el reservorio.

En el grupo de pacientes de estudio se utilizaron expansores de silicona que variaron en volumen entre los 50 y los 600 cc., y en su forma, que fue: rectangular, elíptica, medialuna o modelo Dr. Mario Godoy ${ }^{\circledR}\left(\right.$ Silimed $^{\circledR}$, Río de Janeiro, Brasil).

Dependiendo del tamaño de la lesión, se emplearon 1 o más expansores en un primer tiempo quirúrgico. El reservorio para la administración transcutánea de solución fisiológica se posicionó tunelizado en el plano subcutáneo. Seguidamente se irrigió la zona con solución fisiológica y se cerró los bolsillos con Poliglactina 910 4-0 (Vicryl 4-0 ${ }^{\circledR}$, Ethicon de Johnson \& Johnson, Santiago, Chile) y piel con Nylon 5-0. (Ethilon 4-0 ${ }^{\circledR}$, Ethicon de Johnson \& Johnson, Santiago, Chile).

Todos los pacientes estudiados recibieron profilaxis antibiótica con 1 gr. de cefazolina. A los 15 días de la intervención inicial, se inició la administración transcutánea de solución fisiológica a través del reservorio del expansor, proceso que se denomina activación del expansor. Este tiempo de espera disminuye el riesgo de desplazamiento y extrusión del expansor secundario a dehiscencia de la herida (4). La infiltración se realizó en un intervalo de 4 a 12 semanas dependiendo de la lesión, de forma semanal, administrando entre el 10 y el $25 \%$ del volumen total en cada vez. Este valor corresponde a la velocidad de llenado. Se registró también el volumen de sobrexpansión en cada caso.

Durante los controles semanales se mantuvo informados a los pacientes y a sus familiares sobre la téc-

Tabla II. Datos demográficos de los pacientes intervenidos por defectos en el área craneofacial

\begin{tabular}{|c|c|c|c|c|}
\hline $\begin{array}{l}\text { No de } \\
\text { casos }\end{array}$ & Diagnóstico & Edad prom. & Rango & 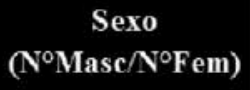 \\
\hline 7 & Nevus melanocítico de cuero cabelludo & 17,7 & $(10-26)$ & $(2-5)$ \\
\hline 5 & Aplasia cuero cabelludo posterior a neurocirugía & 23,8 & $(17-32)$ & $(3-2)$ \\
\hline 3 & Aplasia cuero cabelludo por mordedura de perro & 8,3 & $(5-12)$ & $(3-0)$ \\
\hline 3 & Aplasia cuero cabelludo por quemadura por agua & 8,7 & $(4-15)$ & $(2-1)$ \\
\hline 3 & Nevus melanocítico congénito gigante de cuero cabelludo & 8,7 & $(8-10)$ & $(2-1)$ \\
\hline 2 & Aplasia posterior a tiña capitis & 9,3 & $(9-13)$ & $(1-1)$ \\
\hline 2 & Aplasia cutis & 6 & - & $(1-1)$ \\
\hline 2 & Expansión de microtia & 16,6 & $(13-21)$ & $(1-1)$ \\
\hline 2 & Exposición posterior a craniectomía & 32,5 & $(26-39)$ & $(2-0)$ \\
\hline 2 & Úlcera secundaria a radioterapia por tumor de cuero cabelludo & 33 & $(30-36)$ & $(1-1)$ \\
\hline 1 & Aplasia cuero cabelludo por quemadura eléctrica & 25 & - & $(1-0)$ \\
\hline 1 & Aplasia cuero cabelludo por quemadura por fuego & 9 & - & $(0-1)$ \\
\hline 1 & Aplasia cuero cabelludo por quemadura química & 19 & - & $(0-1)$ \\
\hline 1 & Neurofibromatosis & 37 & - & $(1-0)$ \\
\hline 1 & Reconstrucción nasal & 14 & - & $(0-1)$ \\
\hline 1 & Reconstrucción osteomielitis mandibular & 16 & - & $(1-0)$ \\
\hline 37 & Total & 17,8 & $(4-39)$ & $(21-16)$ \\
\hline
\end{tabular}


nica, el proceso, los riesgos y las dificultades en relación al uso del expansor tisular. Luego, en un segundo acto quirúrgico, una vez lograda la expansión tisular adecuada para cubrir el defecto, se resecó la lesión y se cubrió la zona sin tensión empleando colgajos locales, principalmente de rotación, de avance o ambos.

\section{RESULTADOS}

Durante el período descrito, recopilamos los datos de 37 pacientes con una media de edad de 17,8 años (rango 4 a 39 años), de los cuales 21 fueron varones $(56,8 \%)$ y 16 mujeres $(43,2 \%)$.

Las indicaciones más frecuentes para la reconstrucción de los defectos craneofaciales fueron; nevus melanocítico de cuero cabelludo, aplasia de cuero cabelludo posterior a neurocirugía, mordedura de perro, y secuelas de quemaduras de diferentes orígenes, entre otros (Tabla II).

La ubicación de los expansores fue en su mayoría parietal con 12 casos $(32,4 \%)$, seguida por la ubicación frontal con 8 casos $(21,6 \%)$, en mejilla en 6 casos $(16,2 \%)$, temporal en 5 casos $(13,5 \%)$, auricular en 2 $(5,4 \%)$, occipital en $2(5,4 \%)$ y mastoidea en otros 2 $(5,4 \%)$.

El colgajo más utilizado fue el rectangular $\left(\mathrm{N}^{\circ}=24\right.$; $64,8 \%)$, seguido del de media luna $\left(\mathrm{N}^{\mathrm{o}}=10 ; 27,0 \%\right)$, Dr. Mario Godoy ${ }^{\circledR}\left(\mathrm{N}^{\mathrm{o}}=2 ; 5,4 \%\right)$ y redondo en un paciente $(2,7 \%)$.

Se obtuvo cobertura adecuada del defecto en la totalidad de los casos. En 16 pacientes $(43,2 \%)$ mediante el uso de 2 expansores tisulares; en $15(40,5 \%)$ con 1 expansor; en $4(10,8 \%)$ con 3 y en $2(5,4 \%)$ con 4 expansores.

El volumen promedio de llenado del primer expansor fue de $320 \pm 121 \mathrm{cc}$, el segundo de $284 \pm 76 \mathrm{cc}$, el tercero de $275 \pm 68 \mathrm{cc}$ y por último el cuarto expansor, con un promedio de $325 \pm 106 \mathrm{cc}$. Se realizó sobrexpansión en un $62,2 \%$ de los expansores, aumentando en promedio a $1,3 \pm 2$ veces su capacidad original.

El tiempo promedio utilizado para la expansión craneofacial antes de la cirugía definitiva del total de los pacientes fue de $55 \pm 4$ días, siendo el diagnóstico de reconstrucción facial secundaria a cirugía por osteomielitis mandibular el que más tiempo requirió con 98 días promedio, y el de aplasia de cuero cabelludo por quemadura eléctrica el que menos tiempo requirió, con 28 días en promedio (Fig. 1-3).

El tiempo promedio de cicatrización del total de los pacientes fue de $15,1 \pm 4$ días. Finalmente el tiempo total de tratamiento, desde el ingreso hospitalaria hasta el alta definitiva fue de $70,5 \pm 2$ días, variando en un rango que fue desde los 112 días en el caso de reconstrucción facial posterior a cirugía por osteomielitis, a los 48 días en el caso de aplasia de cuero cabelludo por quemadura eléctrica (Tabla III).

Registramos un total de $35,1 \%$ de complicaciones;
7 se presentaron durante el proceso de expansión correspondiente al 18,9\% del total de la muestra, siendo éstas en su mayoría complicaciones menores: dolor en 4 casos $(10,8 \%)$, hematoma $(2,7 \%)$ e infección $(2,7 \%)$ en casos aislados, y 1 complicación mayor por exposición del expansor $(2,7 \%)$. Tras la retirada del expansor se registraron sólo complicaciones menores en 6 pacientes $(16,2 \%)$, correspondientes a alopecia temporal $(2,7 \%)$ y resultado pobre $(2,7 \%)$ en casos aislados, y cicatriz hipertrófica $(5,4 \%)$ y ensanche de confluencia del expansor $(5,4 \%)$ en 2 casos cada una.

En relación al cuestionario. del total de las preguntas realizadas, el $100 \%$ de los pacientes respondió positivamente respecto a la importancia, utilidad e información recibida sobre el uso de los expansores y durante el proceso. Un $94,6 \%$ de respuestas fueron positivas y un 5,4\% neutras respecto al resultado final de la cirugía. Por otro lado, un $54,1 \%$ de respuestas fueron positivas, $24,3 \%$ neutras y $21,6 \%$ negativas respecto a los tiempos programados. Finalmente, un 54,1\% e los pacientes sí recomendaría este método de expansión tisular a un tercero para resolver algún defecto craneofacial, mientras que el resto no sabe o no lo recomendaría (Gráfica 1).

En cuanto a la escala de valoración de Strasser (14), 35 pacientes $(94,6 \%)$ puntuaron su resultado como "buen resultado" (puntación entre 1 a 4), mientras que solo 2 pacientes $(5,4 \%)$ puntuaron su resultado como "mediocre", correspondiendo a 1 caso de aplasia de cuero cabelludo secundaria a quemadura eléctrica (puntuación=5), y 1 caso de úlcera secundaria a radioterapia por tumor de cuero cabelludo (puntuación=5). No hubo resultado "pobre" según esta escala.

\section{Discusión}

En la actualidad, el abordaje de los defectos craneofaciales mediante expansión tisular se centra en la búsqueda de resultados excelentes. Además de proporcionar una cobertura adecuada, se pretende preservar tanto los patrones de redirección normal de los folículos pilosos como la línea de implantación de pelo original (7). Este método presenta la ventaja de disponer de tejido de similar color, textura y de pelo de buena calidad. La visualización microscópica del tejido expandido presenta una epidermis de similar grosor a expensas de un aumento del metabolismo, una dermis y tejido celular subcutáneo de menor grosor pero con un aumento de la síntesis de colágeno en dermis, y un aumento de la vascularización similar al que se observa en los colgajos de retardo (15-17).

En la mayoría de los casos, los defectos del área craneofacial se resuelven mediante colgajos de rotación, de avance o ambos. Sólo cuando la zona a tratar es muy extensa, está dañada, o simplemente no es suficiente para la obtención de un resultado estético óptimo, la expansión tisular resulta ser la técnica quirúrgica de elección. Cabe 


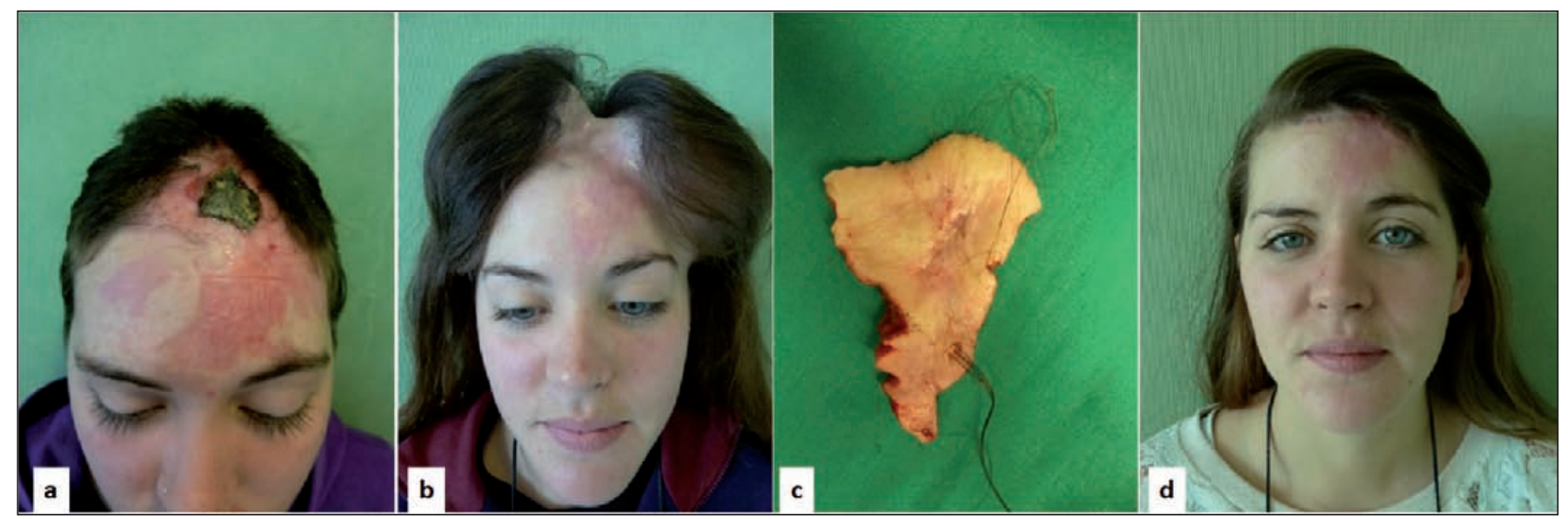

Fig. 1. A: Paciente de 19 años con secuela cicatricial en cuero cabelludo secundaria a quemadura química. B: Proceso de expansión tisular durante 11 semanas mediante el uso de 2 expansores rectangulares hasta un volumen total de 265 cc cada uno. C: Resección de tejido cicatricial. D: Resultado final tras 3 meses de tratamiento.

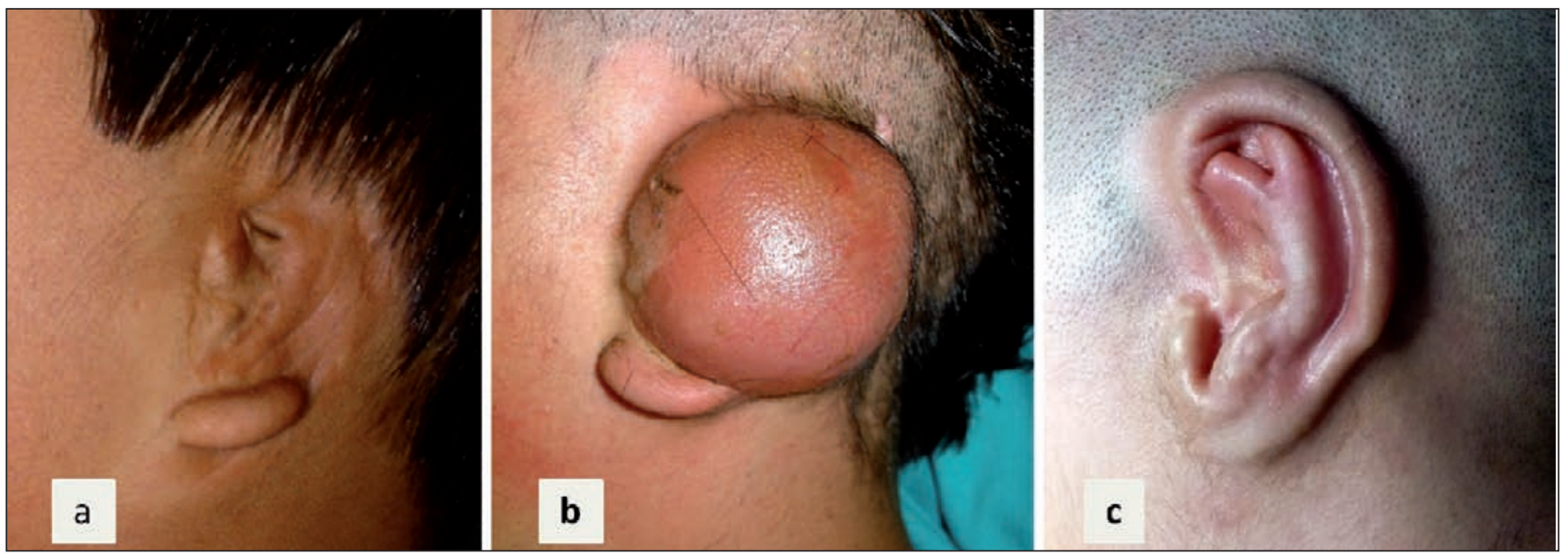

Fig. 2. A: Paciente de 13 años con antecedente de microtia unilateral izquierda operada con reabsorción de marco cartilaginoso. B: Proceso de expansión tisular durante 7 semanas mediante el uso de 1 solo expansor modelo Dr. Mario Godoy ${ }^{\circledR}$ hasta un volumen total de 50 cc. C: Resultado final tras 3 meses de postoperatorio.

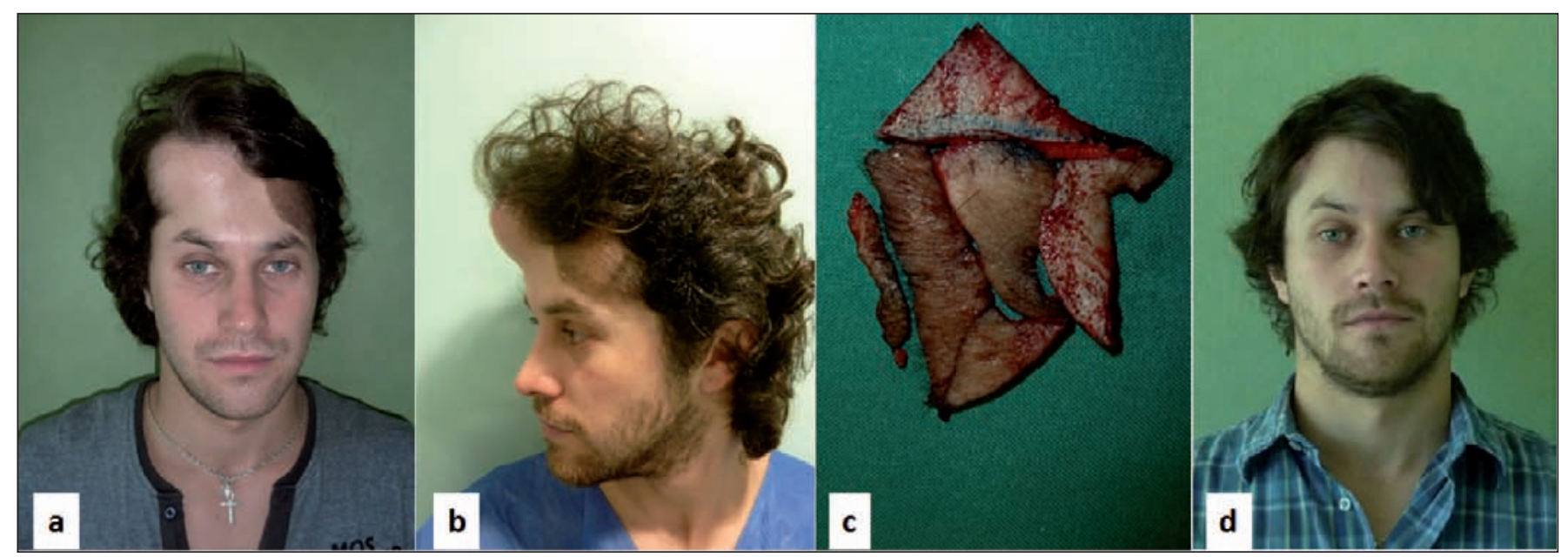

Fig. 3: A y B: Paciente de 20 años con nevus melanocítico de cuero cabelludo, vista frontal y lateral. Proceso de expansión tisular durante 5 semanas con uso de un expansor rectangular de $400 \mathrm{cc}$. C: Resección del nevus. D: Resultado final tras 3 meses de postoperatorio.

destacar que para los casos de pérdida masiva de partes blandas secundarios a daño térmico, con exposición ósea y sobre todo cuando el defecto presenta áreas de necrosis, se debe considerar la cobertura con colgajos libres (18).
En cuanto a las complicaciones, varían en la literatura consultada entre el 10 al 33\%. $(4,6,7,15,16)$. Probablemente, el diagnóstico constituye un factor de riesgo al comparar que 2 trabajos, los de Buhrer y col.(8) y Leigh- 
ton y col (15), obtuvieron valores del 10 a $17 \%$ respectivamente en estudios en los que se utilizaron expansores para el tratamiento de alopecia, mientras que los estudios de Gosain y col. (4) y Bauer y col. (16), muestran un promedio de complicaciones del $25 \%$ y el $33 \%$ respectivamente para el tratamiento de nevus congénitos gigantes. Friedman y col. (6) demostraron que el tipo de diagnóstico, la edad de los pacientes, el uso de reservorios o válvulas internos y la historia previa de uso de expansor, son factores de riesgo para desarrollar complicaciones; mien- tras que el uso de antibióticos en el intraoperatorio, el sexo del paciente y el número de expansores utilizados, no mostraron significancia estadística. A su vez, según Hallock $(9,10)$, el volumen de sobrexpansión no constituye un factor de riesgo, y es posible sobrexpandir el expansor en varias veces su capacidad máxima indicada manteniendo su integridad estructural. Friedman y col. (6) categorizan las complicaciones en mayores y menores, correspondiendo las primeras a todo evento adverso que signifique un acto quirúrgico adicional. En su trabajo,

Gráfica 1. Porcentaje de respuestas positivas, neutras y negativas sobre el uso de expansores tisulares en el área craneofacial, obtenidas del cuestionario aplicado a la totalidad de los pacientes intervenidos

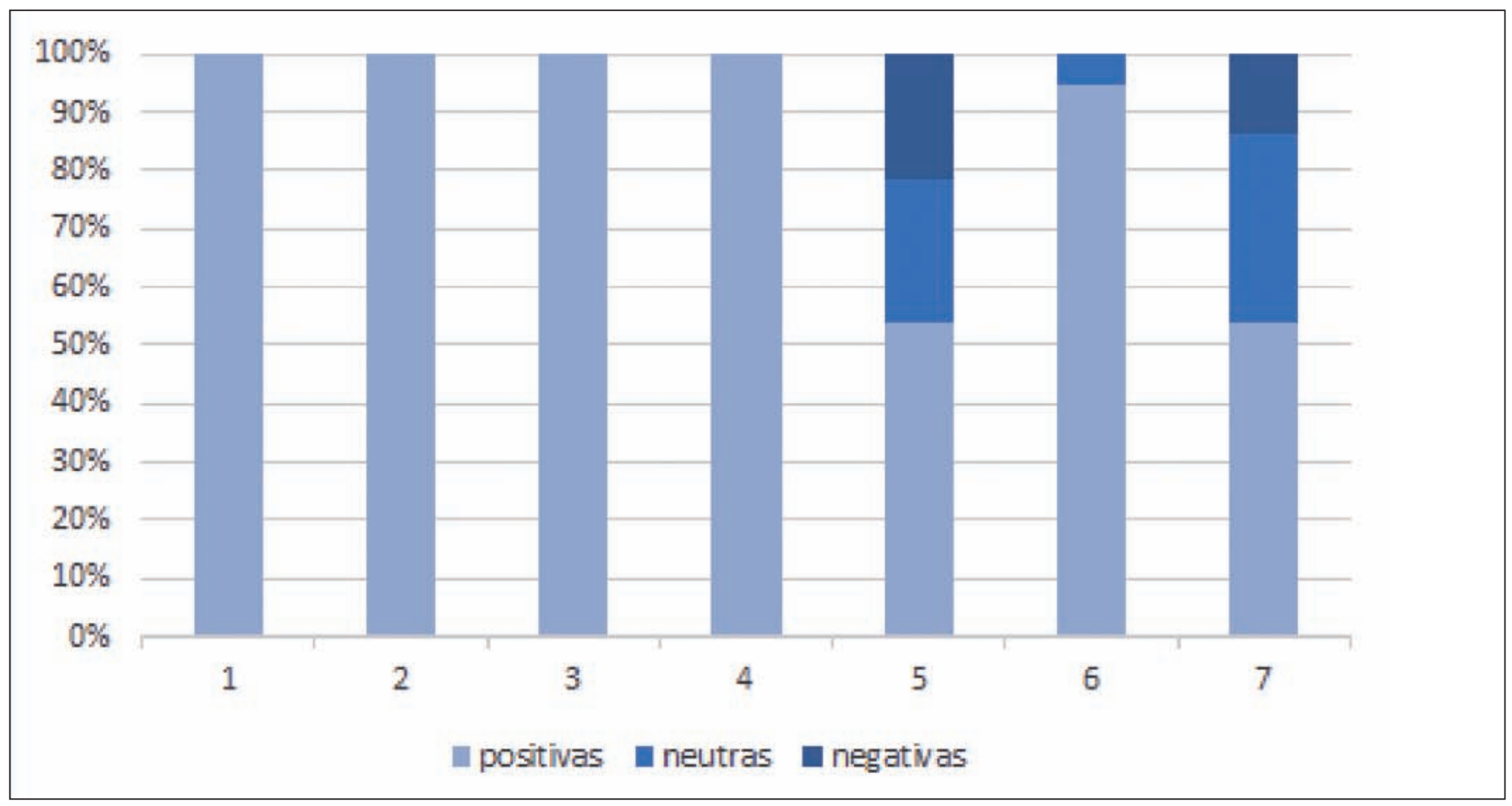

Tabla III. Resumen de la totalidad de los pacientes intervenidos por defectos en el área craneofacial. Se agruparon según diagnóstico, tiempo de expansión tisular, de cicatrización y total de tratamiento

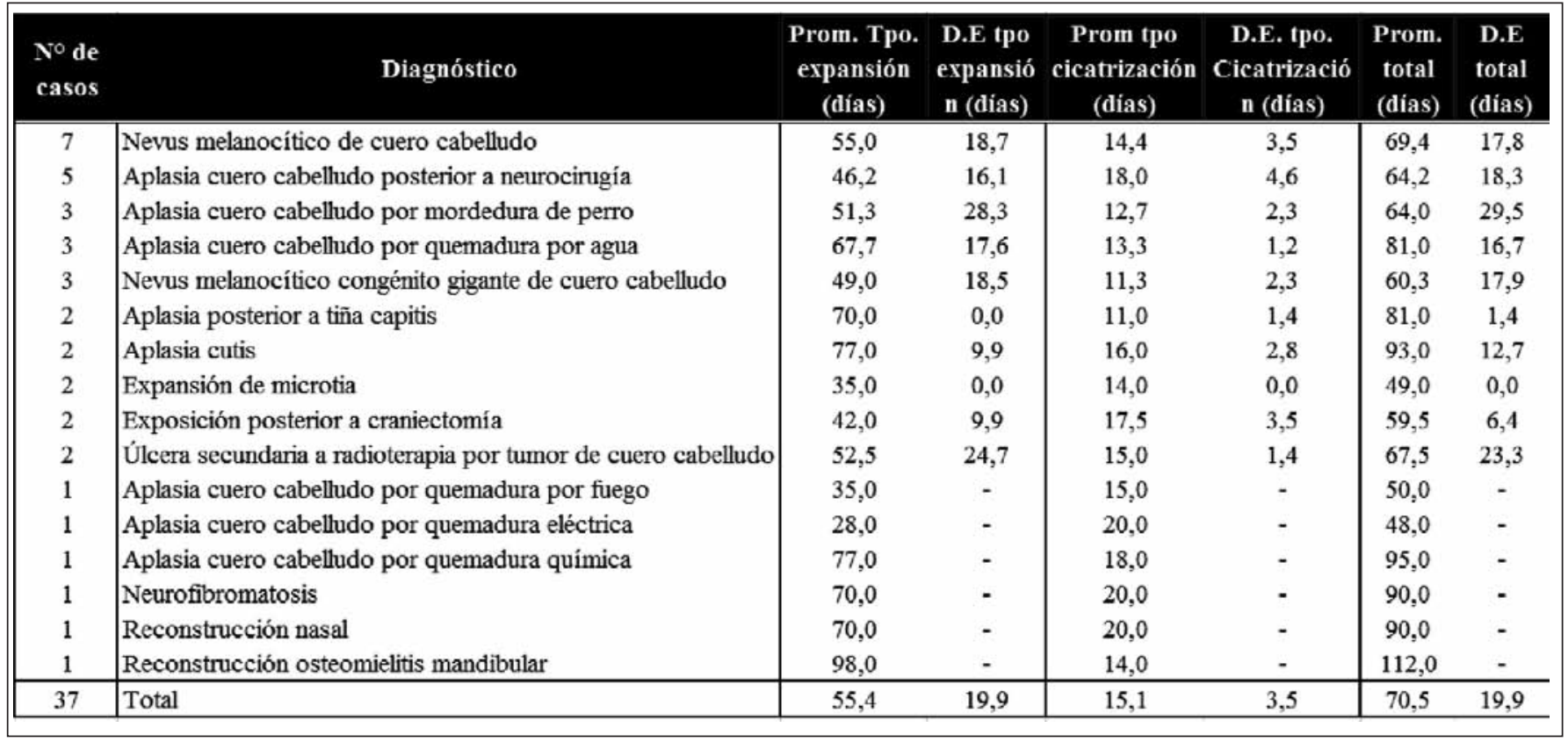


sobre una muestra de 82 pacientes pediátricos en los que se utilizaron expansores tisulares con indicación y localización heterogénea, muestran un porcentaje de complicaciones mayores y menores de un $9 \%$ para ambos conceptos. Nuestro estudio obtuvo un porcentaje de complicaciones total del $35,1 \%$, correspondiendo sólo el 2,7\% (1 caso) a una complicación mayor por exposición del expansor. Dentro de las complicaciones menores lideró el dolor, con un total del 10,8\% (4 casos). Estos datos resul$\tan$ favorables al considerar que nuestra muestra era heterogénea en cuanto a las indicaciones, y que abarcaba diagnósticos de los cuales se podría esperar un mayor número de complicaciones según la literatura al respecto, como son las aplasias de cuero cabelludo, las quemaduras y los nevus congénitos gigantes. A su vez, obtuvimos un porcentaje bajo de complicaciones mayores. A pesar de ello, consideramos que es necesario aumentar la muestra e incluir otros diagnósticos, así como homogenizar la muestra en número de pacientes por patología, para poder concluir que corresponde al promedio global de complicaciones y considerar otras variables, como por ejemplo, el lugar de instalación del expansor como posible factor de riesgo independiente.

El diseño del cuestionario nos parece adecuado para evaluar distintos aspectos del uso y proceso de expansión tisular. A pesar de la apreciación favorable por parte de los pacientes de nuestro grupo de estudio en aspectos tales como la importancia, utilidad e información recibida respecto al uso de los expansores y su proceso, así como respecto al resultado final de la cirugía, concordante además por la obtención de una puntuación en la escala de Strasser menor de 4 en el 94,6\% del total de los pacientes, un porcentaje del $45,9 \%$ de los pacientes se mostró indiferente o definitivamente no recomendaría a un tercero que presentase su mismo problema someterse a este tipo de cirugía, lo cual se podría explicar por el hecho de tratarse de un proceso que demanda tiempo y compromiso por parte del paciente, y por presentar temporalmente deformidades craneofaciales durante el proceso de expansión que finalmente desgastan al paciente.

Hasta donde hemos podido revisar, no hemos encontrado en la literatura registros de la aplicación de un cuestionario para este tipo de procedimiento quirúrgico y patología en particular. Dados los resultados, consideramos que podría tenerse en cuenta para otros trabajos similares.

La relación médico-paciente cobra particular importancia en la aplicación de expansión tisular a nivel craneofacial, ya que los pacientes pueden manifestar trastornos de carácter emocional causados por la deformidad antiestética temporal durante los 2 meses que como promedio dura la etapa preoperatoria. Además, resulta crucial para mantener una adecuada adhesión del paciente al proceso ya que éste debe asistir semanalmente a control con el médico para el llenado del expansor. Por otra parte, el rol del médico tratante no es menor ya que con- siderando el tiempo otorgado a cada paciente (70 días en promedio), éste estuvo prácticamente siempre tratando a un paciente mediante esta técnica durante el período del estudio, ya fuera realizando el proceso de expansión tisular, o cuidando del postoperatorio.

\section{Conclusiones}

A pesar de que nuestro grupo de pacientes de estudio corresponde a una muestra heterogénea, se logró un buen resultado final en la reparación de los defectos craneofaciales, con un bajo porcentaje de complicaciones mayores y un alto porcentaje en el grado de satisfacción de los pacientes en relación al resultado de la cirugía. Mediante el cuestionario diseñado por nuestro equipo de trabajo fue posible analizar y obtener información sobre la opinión de los pacientes acerca del proceso de expansión, por lo que consideramos que éste método de valoración final podría incorporarse por otros autores en futuros trabajos.

\section{Dirección del autor}

Dr. Juan Pablo Sorolla P.

Agustín de Negri 5241

Santiago. Chile

e-mail: jpsorolla@gmail.com

\section{Bibliografía}

1. Radovan C.: Tissue expansion in soft-tissue reconstruction. Plast Reconstr Surg 1984; 74(4): 482-490.

2. Centeno M, Centeno C.: Expansores Tisulares: Conceptos Generales. Acta Médica Costarricense 000; 42(3): $109-114$

3. Vendroux J, Ascherman JA, Lacroix P, et al.: Obtaining maximal use of expanded scalp rotation flaps via an experimental model. Plast Reconstr Surg 1997; 99(4): 1000-1005.

4. Gosain A.: Refinement of tissue expansion for pediatric forehead reconstruction: a 13 year experience. Plast $R e$ constr Surg. 2009; 124(5): 1559-1570.

5. Kawashima T.: Problems in the use of tissue expanders for scalp reconstruction. Plast Reconstr Surg. 1988; 6: 513-522.

6. $\quad$ Friedman R.: Risk factor for complication in pediatric tissue expansion. Plast Reconstr. Surg. 1995; 98(7): 1242-1246.

7. Leedy J.: Reconstruction of acquired scalp defects: an algorithmic approach. Plast Reconstr. Surg. 2005; 116; (4): $54 \mathrm{e}-72 \mathrm{e}$.

8. Buhrer DP, Huang TT, Yee HW, et al.: Treatment of burn alopecia with tissue expanders in children. Plast Reconstr Surg. 1988;81(4):512-515.

9. Hallock GG.: Safety of clinical overinflation of tissue expanders. Plast Reconstr Surg. 1995;96(1):153-157.

10. Hallock GG.: Maximum overinflation of tissue expanders. Plast Reconstr Surg. 1987;80(4):567-569.

11. Likert RA.: A technique for the measurement of attitudes. Arch Psychol. 1932;140:1-55. 
12. Sudore RL, Stewart AL, Knight SJ, et al.: Development and validation of a questionnaire to detect behavior change in multiple advance care planning behaviors. PLoS One. 2013,5;8(9):1-8.

13. Chiasson PM, Pace DE, Schlachta CM, et al.: Minimally invasive surgical practice: a survey of general surgeons in Ontario. Can J Surg. 2004;47(1):15-19.

14. Strasser EJ.: Application of an Objective Grading System for the Evaluation of Cosmetic Surgical Results. Plast Reconstr Surg 1999;104(7):2282-2285.

15. Leighton WD, Johnson ML, Friedland JA.: Use of the temporary soft-tissue expander in posttraumatic alopecia. Plast Reconstr Surg. 1986;77(5):737-743.
16. Bauer BS, Few JW, Chavez CD, et al.: The role of tissue expansion in the management of large congenital pigmented nevi of the forehead in the pediatric patient. Plast Reconstr Surg. 2001;107(3):668-675.

17. Austad E.: Tissue Expansion: Pathophysiology. In M. Habal (Ed.), Advances in Plastic Surgery, Vol 1. 1. Chicago: Year Book Publishers, 1984. P. 113.

18. Pereira N. et al.: Experiencia en el tratamiento de quemaduras de cuero cabelludo. Cir plást iberolatinoam., 2013,39 (1): 61-65. 